\title{
Synthesis of Iron-Modified Biochar Derived from Rice Straw and Its Application to Arsenic Removal
}

\author{
Thi Hanh Nguyen $\mathbb{D}^{1},{ }^{1}$ Thi Huong Pham, ${ }^{2}$ Hong Tham Nguyen Thi, ${ }^{3}$ Thi Nham Nguyen $\mathbb{D}$, ${ }^{4,5}$ \\ Minh-Viet Nguyen $\mathbb{D}^{5}{ }^{5}$ Trinh Tran Dinh $\mathbb{D}^{5}{ }^{5}$ Minh Phuong Nguyen $\mathbb{D}^{5},{ }^{5}$ Trung Quang Do $\mathbb{D}^{\circ},{ }^{5}$ \\ Thao Phuong $\mathbb{D},{ }^{5}$ Thu Trang Hoang, ${ }^{5}$ Thanh Tung Mai Hung, ${ }^{6}$ and Viet Ha Tran Thi $\mathbb{D}^{7}$ \\ ${ }^{1}$ Faculty of Environment, University of Science, Vietnam National University, 334 Nguyen Trai, Thanh Xuan, Hanoi, Vietnam \\ ${ }^{2}$ Center for Advanced Chemistry, Institute of Research and Development, Duy Tan University, Da Nang, Vietnam \\ ${ }^{3}$ NTT Hi-Tech Institute, Nguyen Tat Thanh University, Ho Chi Minh City, Vietnam \\ ${ }^{4}$ Center for Analytical Sciences Development and Application, Vietnam National University, Thanh Xuan, Hanoi, Vietnam \\ ${ }^{5}$ Faculty of Chemistry, University of Science, Vietnam National University, Thanh Xuan, Hanoi, Vietnam \\ ${ }^{6}$ Faculty of Chemical Engineering, Ho Chi Minh City University of Food Industry, 140 Le Trong Tan, Ho Chi Minh City, Vietnam \\ ${ }^{7}$ Vietnam-Japan University, Vietnam National University, Hanoi, Vietnam
}

Correspondence should be addressed to Thi Nham Nguyen; nguyenthinham_t57@hus.edu.vn

Received 14 March 2019; Revised 20 May 2019; Accepted 13 September 2019; Published 16 October 2019

Guest Editor: Ajit Kumar Sharma

Copyright (c) 2019 Thi Hanh Nguyen et al. This is an open access article distributed under the Creative Commons Attribution License, which permits unrestricted use, distribution, and reproduction in any medium, provided the original work is properly cited.

\begin{abstract}
A novel iron-modified biochar (FMBC) derived from rice straw was synthesized using $\mathrm{FeCl}_{3}$ modification for efficient As(V) removal from aqueous solution. FTIR and SEM-EDX analyses were carried out to determine the mechanism involved in the removal process and also demonstrated that Fe had loaded successfully on the surface of modified biochar. The iron-modified biochar showed higher arsenic removal ability than the raw biochar. The iron-modified biochar showed a maximum adsorption with an initial solution $\mathrm{pH}$ of 5.0. Moreover, for the tested biochar, the $\mathrm{As}(\mathrm{V})$ removal kinetics data were well fitted by the pseudosecond-order model. Furthermore, the As(V) removal data upon being well fitted by the Langmuir model showed the maximal removal capacity of $28.49 \mathrm{mg} / \mathrm{g}$. The simple preparation process and high adsorption performance suggest that the iron-modified biochar derived from rice straw could be served as an effective, inexpensive, and environmentally sustainable adsorbent to replace typical granular activated carbon (AC) for As(III) removal from aqueous solution.
\end{abstract}

\section{Introduction}

Arsenic is one of the most abundant elements in the biosphere and in the Earth's crust. Arsenic occurs in most natural waters as $\mathrm{As}(\mathrm{V}), \mathrm{As}(\mathrm{III})$, As (0), and $\mathrm{As}(-\mathrm{III})$ oxidation states. As-contaminated water affects a large group of population worldwide, particularly in Vietnam, China, and India. Chronic exposure to inorganic arsenic may lead to cancer or noncancer health effects [1]. Arsenic has been classified as a Class A carcinogen by the United States Environmental Protection Agency (USEPA). According to the World Health Organization (WHO) and USEPA, the limitations for As concentration are $10 \mu \mathrm{g} / \mathrm{L}$ and $0.2 \mathrm{mg} / \mathrm{L}$ in safe drinking water and discharge wastewater, respectively [2]. Ingestion of arsenic, even at low concentration, has resulted in various detrimental health issues such as pulmonary disease, cardiovascular disease, nervous system dysfunction, and also cancer of the lung kidney and skin [3].

Coagulation/precipitation, ion exchange, reverse osmosis, and adsorption processes were utilized for arseniccontaminated water remediation [4-6]. Among the various techniques, adsorption has been considered the most common and effective technology for removing contaminants from groundwater or wastewater [7]. Adsorption is often utilized at the end of a treatment plan for removal of 
contaminants because of its low cost, and it does not generate any secondary waste that needs further treatment.

Biochar (BC), a carbon material produced mainly from the pyrolysis process of low-cost biomass residuals such as rice straw, has received much recent attention because of its many potential environmental abilities such as carbon sequestration, soil improvement, water treatment, and environmental remediation $[8,9]$. BC can be utilized as an adsorbent because of its porosity, large surface area, and negative surface charge that can be useful for decontaminating water (organic and inorganic pollutants) [10]. Some BCs can be utilized for removal of heavy metal ions or organic polluted compounds in the aqueous solution. However, the lack of adsorption sites and functional group limits its application to As removal $[11,12]$. Many researchers have modified BCs to improve their properties such as enhance the surface functional groups for effective adsorption [13, 14]. Several studies have utilized metal oxyhydroxide surfaces and clay minerals containing Fe, Mn, $\mathrm{Al}, \mathrm{Cu}$, and $\mathrm{Co}$ to remove As in the aqueous solution [15]. Hematite, an abundant and natural Fe mineral, was a good adsorbent for As removal from groundwater [16]. The hematite mineral was activated by the thermal method to enhance its ability to remove aqueous As [17].

Vietnam is the world's fifth largest rice producer all over the world. The total amount of rice straw generated was approximately 67 million dry ton in 2013. In order to reduce the environmental problem from rice straw burning, it is necessary to find a suitable method to remove the excess rice straw. Therefore, biochar derived from rice straw can be an effective, inexpensive, and environmentally sustainable adsorbent for environmental treatment and can reduce atmospheric pollution from rice straw burning.

In the present study, dried rice straw was used for the preparation of biochar by slow pyrolysis and then modified with the mixture of $\mathrm{FeCl}_{3}$ and $\mathrm{FeSO}_{4}$ before being applied for the removal of $\mathrm{As}(\mathrm{V})$ in aqueous solution.

\section{Materials and Methods}

2.1. Biochar Production. In this study, the rice straw biomass was collected from a rice farm in the city of Hanoi, Vietnam. It was pyrolyzed at a temperature of $500^{\circ} \mathrm{C}$ for $1 \mathrm{~h}$ using a tube-type electrical furnace under $\mathrm{N}_{2}$ gas. The biochar was collected from the reactor after being cooled till a room temperature of $25-30^{\circ} \mathrm{C}$ inside the muffle furnace. The iron-modified biochar was synthesized by the following procedure. $10 \mathrm{~g}$ of the obtained $\mathrm{BC}$ was mixed with $500 \mathrm{ml}$ of $7.3 \mathrm{~g} \mathrm{FeSO}_{4} \cdot 7 \mathrm{H}_{2} \mathrm{O}$ and $7.23 \mathrm{~g} \mathrm{FeCl}_{3} \cdot 6 \mathrm{H}_{2} \mathrm{O}$ in a glass tube. This mixture was heated at $50^{\circ} \mathrm{C}$ to form a stable suspension. The $\mathrm{pH}$ was raised to 11 by adding $0.05 \mathrm{M} \mathrm{NaOH}$ solution, dropwise. After mixing for $60 \mathrm{~min}$, the organic residues were removed by washing with distilled water $\left(\mathrm{H}_{2} \mathrm{O}\right)$ until the $\mathrm{pH}$ of the washing solution reached 7.0. The fine powdered modified biochar (FMBC) was vacuum-filtered and then dried overnight at $50^{\circ} \mathrm{C}$ in a hot air oven [18].
2.2. Characterization of Biochar $(B C)$. The surface architecture of the synthesized BC (FMBC) was examined using a JED-2300 Analysis Station Plus (JEOL) scanning electron microscope (SEM). Energy-dispersive X-ray (EDX) spectroscopy analyses were carried out using a Quantax instrument (Bruker, USA). The infrared (IR) spectra of synthesized materials (as $\mathrm{KBr}$ pellets) were analyzed. The surface functional groups of FMBC were analyzed by using an IR spectrophotometer (PerkinElmer FTIR, USA) with an attenuated total reflectance attachment within the wavelength of $400-4,000 \mathrm{~cm}^{-1}$.

The point of zero charge (PZC) of FMBC was determined by using the $\mathrm{pH}$ drift method of $0.01 \mathrm{M} \mathrm{NaCl} \mathrm{pH}$ interval of 2 and in the range of $\mathrm{pH} 2$ to 12 [19]. The $\mathrm{pH}$ values of solutions were adjusted between 2 and 12 by using $0.1 \mathrm{M} \mathrm{HCl}$ or $0.1 \mathrm{M} \mathrm{NaOH}$ solution. The initial $\mathrm{pH}$ values of solutions were measured. A $0.2 \mathrm{~g}$ of biochar was added into a beaker with $20 \mathrm{~mL}$ of $\mathrm{NaCl}$ solution and left undisturbed for $24 \mathrm{~h}$ under $\mathrm{N}_{2}$ bubbles to prevent $\mathrm{CO}_{2}$ dissolution until the $\mathrm{pH}$ value became stable, and then final $\mathrm{pH}$ of the solutions was measured. The final $\mathrm{pH}$ was measured, and $\mathrm{pH}_{\mathrm{PZC}}$ was determined as the value at which $\mathrm{pH}_{\text {final }}=\mathrm{pH}_{\text {initial }}$.

2.3. Batch Sorption of Arsenic. Adsorption experiments were conducted to determine the isotherms of arsenic sorption onto the FMBC sample. About $0.2 \mathrm{~g}$ of the FMBC was mixed with $100 \mathrm{~mL}$ of $\mathrm{As}(\mathrm{V})$ solution for each experiment. The mixture was then shaken in a mechanical shaker $(120 \mathrm{rpm})$ at room temperature $\left(22 \pm 2^{\circ} \mathrm{C}\right)$. At the end of each experiment, the remaining As concentrations were determined by using inductively coupled plasma mass spectrometry (ICP-MS) after vacuum-filtered. Duplicate sets of samples were taken for the analysis of residual concentration of As, and the difference of two measurements should be smaller than $10 \%$. All chemical reagents used in the experiments were of high purity grade from Sigma-Aldrich.

The amount of As(V) adsorbed onto the FMBC (adsorbent) was calculated by the concentration difference between the initial and final concentrations of the solution by using the following equation:

$$
q_{\mathrm{e}}\left(\mathrm{mg} \cdot \mathrm{g}^{-1}\right)=\left[C_{\mathrm{o}}-C_{\mathrm{e}}\left(\mathrm{mg} \mathrm{L}^{-1}\right)\right] \times V(\mathrm{~L}) / W(\mathrm{~g}) .
$$

Hence, $q_{\mathrm{e}}$ is the equilibrium amount of the $\mathrm{As}(\mathrm{V})$ adsorbed $\left(\mathrm{mg} \cdot \mathrm{g}^{-1}\right)$ on the FMBC, $C_{\mathrm{o}}$ and $C_{\mathrm{e}}$ are the initial and equilibrium concentration of $\mathrm{As}(\mathrm{V})(\mathrm{mg} / \mathrm{L}), V$ is the solution volume of the test sample (L), and $M$ is the total mass of Fe-modified BC added (g).

2.4. Adsorption Isotherms and Kinetic Models. The equilibrium adsorption isotherms were utilized to determine the adsorption mechanism. In this study, Langmuir isotherm and Freundlich isotherm models were utilized to analyze the adsorption process of biochar. Langmuir isotherm is valid for monolayer sorption and expressed in the following equation: 


$$
\frac{c_{\mathrm{e}}}{q_{\mathrm{e}}}=\frac{1}{q_{\max } K_{\mathrm{L}}}+\frac{c_{\mathrm{e}}}{q_{\max }},
$$

where $q_{\max }\left(\mathrm{mg} \cdot \mathrm{g}^{-1}\right)$ indicates the monolayer adsorption capacity and $K_{\mathrm{L}}\left(\mathrm{L} \cdot \mathrm{mg}^{-1}\right)$ is the heat of adsorption. The favorability or unfavorability of Langmuir adsorption can be expressed by

$$
R_{\mathrm{L}}=\frac{1}{1+K_{\mathrm{L}} C_{0}},
$$

where $R_{\mathrm{L}}$ indicates favorable adsorption and has the range between 0 and 1 .

A Freundlich isotherm describes the heterogeneous surface energies by multilayer adsorption and is expressed in the following equation:

$$
\log q_{\mathrm{e}}=\log K_{\mathrm{F}}+\frac{1}{n} \log C_{\mathrm{e}},
$$

where $K_{\mathrm{F}}$ expresses the adsorption capacity $\left(\mathrm{mg}^{-\mathrm{g}^{-1}}\right)$ and $n$ is an empirical parameter related to the adsorption intensity, which varies with the heterogeneity of the adsorbent. The increase in $1 / n$ enhanced the adsorption favorability.

The adsorption kinetic is an important characteristic influencing the adsorption efficiency. The pseudo-first-order and pseudo-second-order kinetic models express the adsorption process as follows:

$$
\begin{array}{rlrl}
\ln \left(q_{\mathrm{e}}-q_{t}\right) & =\ln q_{\mathrm{e}}-k_{1} t, \quad & \quad(\text { pseudo }- \text { first }- \text { order model }), \\
\frac{t}{q_{t}} & =\frac{1}{k_{2} q_{\mathrm{e}}^{2}}+\frac{1}{q_{\mathrm{e}}} t, \quad(\text { pseudo }- \text { second }- \text { order model }),
\end{array}
$$

where $q_{\mathrm{e}}$ and $q_{t}\left(\mathrm{mg}^{\mathrm{g}} \mathrm{g}^{-1}\right)$ are concentrations adsorbed at equilibrium and at different time $t$ and the parameters $k_{1}$ $\left(\mathrm{min}^{-1}\right)$ and $k_{2}\left(\mathrm{~g} \cdot \mathrm{mg}^{-1} \mathrm{~min}^{-1}\right)$ are the equilibrium rate constants of pseudo-first-order and pseudo-second-order kinetic models, respectively.

\section{Results and Discussion}

3.1. Characteristics of BCs. The SEM analysis was investigated for the determination of shape, size, and surface morphological structure of the raw biochar (RB) and FMBC. Figure 1 reveals the surface morphologies of the two samples are distinctly different. The Fe-modified biochar showed more heterogeneous structure than the raw biochar after modification process that can contribute to enhance the sorption of $\operatorname{As}(\mathrm{V})$ in the aqueous solution [20].

The FTIR spectrum of RB and FMBC is shown in Figure 2, representing the functional groups on the $\mathrm{RB}$ and FMBC material introduced by the chemical modification process. The peaks found in the spectrum of the RB and FMBC show almost similar wavenumbers. Several peaks obtained around wavenumbers 1,605 and $1,379 \mathrm{~cm}^{-1}$, which were assigned to $\mathrm{C}=\mathrm{O}$ and $\mathrm{C}-\mathrm{O}$ peaks that were attributed to carboxyl and lactone functional groups, respectively [21]. The peaks at 3,409 and $1094 \mathrm{~cm}^{-1}$ correspond to vibration of $\mathrm{O}-\mathrm{H}$ of the adsorbent [22]. Vibration of the Fe-O peak was observed on the FMBC at $780 \mathrm{~cm}^{-1}$. These FTIR results indicated that the chemical modification plays an important role in the changing properties of biochar. The modification process enhanced the functional group intensity on the surface of the biochar; thus, these functional groups can be new active sites for the adsorption improvement on the biochar. The EDX spectra of the RB and FMBC (Figure 3) further indicated the increasing $\mathrm{Fe}$ content on the biochar surface after modification. It revealed that magnetite was added to the biochar surface after the modification process.

The point of zero charge (PZC) of a biochar determines the $\mathrm{pH}$ at which the surface of the biochar has positive or negative charge [23]. In this work, the points of zero charge of $\mathrm{RB}$ and FMBC were 5.44 and 6.88, respectively (Figure 4). The acidic value of the FMBC indicated that arsenic removal is feasible below this $\mathrm{pH}$ because the net positively charged surfaces are favorable to attract the anions.

3.2. Effect of Initial Solution pH. A pH solution is an important adsorption parameter for the adsorption study because the $\mathrm{pH}$ solution demonstrates the $\mathrm{H}^{+}$ions of specific functional groups on the biochar surface and varies the form of As in the solution. $\mathrm{pH}_{\mathrm{PZC}}$ also plays an important role in the adsorption process. At $\mathrm{pHs}<\mathrm{pH}_{\mathrm{PZC}}$, the surface of the FMBC is positively charged and gives a strong electrostatic attraction between surface groups and anion species in the solution that could enhance the adsorption process. The decrease in the adsorption amount observed at $\mathrm{pH}$ higher than $\mathrm{pH}_{\mathrm{PZC}}$ (when the surface of the adsorbent is negatively charged) could lead to increased competition between $\mathrm{OH}^{-}$ and anion species for the adsorption sites [24]. The effect of solution $\mathrm{pH}$ on the adsorbent's arsenic sorption (removal) was identified by varying the initial solution $\mathrm{pH}$ while keeping other sorption parameter constants. The $\mathrm{pH}$ effect on adsorption was determined by mixing $1.0 \mathrm{~g}$ of modified BC with $100 \mathrm{ml}$ of a $10 \mathrm{mg} / \mathrm{l} \mathrm{As}(\mathrm{V})$ solution at various $\mathrm{pH}$ values ranging from 2.0 to 8.0 for $120 \mathrm{~min}$.

The $\mathrm{pH}$ effect ranging from 2.0 to 8.0 , on the adsorption of $A s(\mathrm{~V})$ on biochar, is shown in Figure 5. The removal of $\mathrm{As}(\mathrm{V})$ ions was relatively low in the alkaline solution $(\mathrm{pH}>6.8)$ compared with that at lower $\mathrm{pH}$ values, ranging from $\mathrm{pH} 2.0$ to $6.8\left(\mathrm{pH}_{\mathrm{PZC}}\right)$, because the $\mathrm{OH}^{-}$ions at alkaline conditions can compete with $\mathrm{As}(\mathrm{V})$ anion for active sites under strong alkaline conditions, resulting in the blocking of $\mathrm{As}(\mathrm{V})$ adsorption on the surface of the modified BC. This is because $\mathrm{As}(\mathrm{V})$ existed in the aqueous solutions in the form of $\mathrm{H}_{3} \mathrm{AsO}_{4}, \mathrm{H}_{2} \mathrm{AsO}_{4}{ }^{-}, \mathrm{HAsO}_{4}{ }^{2-}, \mathrm{AsO}_{4}{ }^{3-}$, and especially $\mathrm{H}_{2} \mathrm{AsO}_{4}{ }^{-}$at the $\mathrm{pH}$ range of 2.0-6.0 [25]. Therefore, increasing the initial concentration of proton in aqueous solutions increased the level of $\mathrm{As}(\mathrm{V})$ removal under acid conditions, ranging from $\mathrm{pH} 2.0$ to 6.8. The highest removal efficiency was 86.3 and $62.3 \%$ for FMBC at the condition of $\mathrm{pH}<6.0$ and $\mathrm{pH}>6.0$, respectively. The $\mathrm{RB}$ showed lower removal efficiency even under the condition of $\mathrm{pH}<5.0$. This demonstrates the feasibility of the FMBC for $\mathrm{As}(\mathrm{V})$ removal from wastewater with $\mathrm{pH}$ values in the range of $4-7$. 

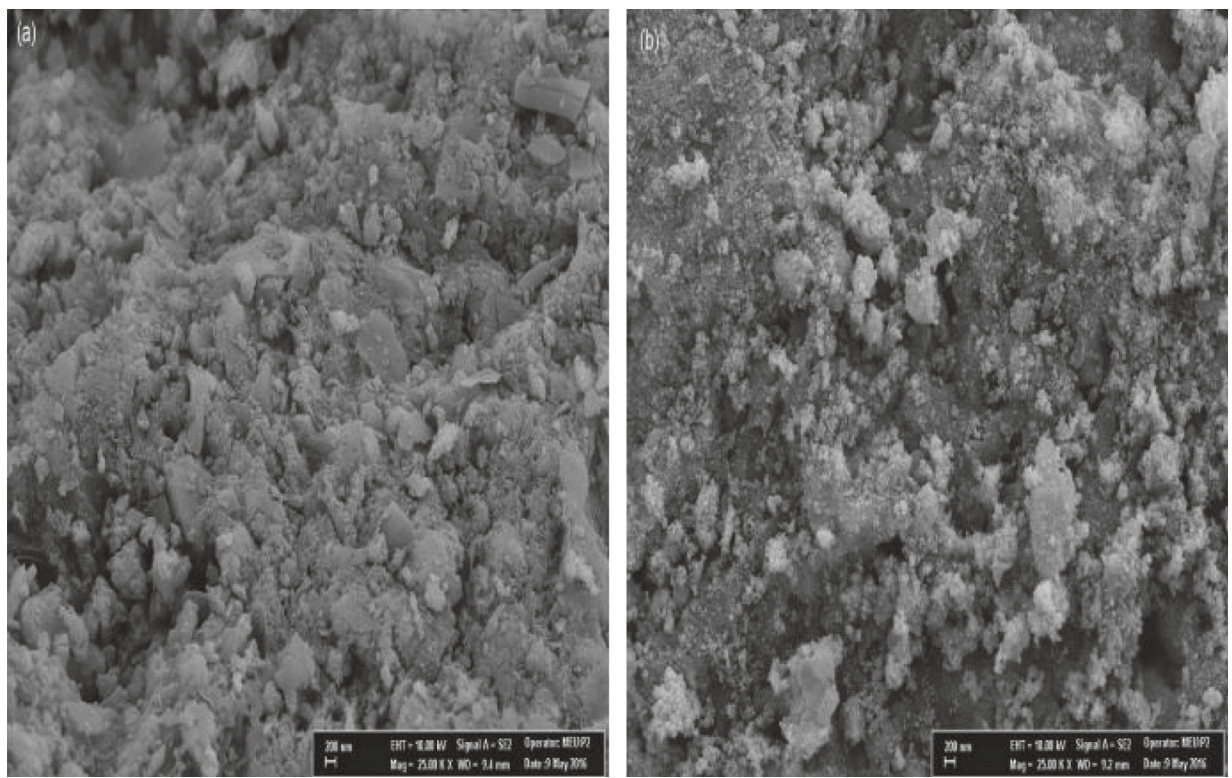

FIGURE 1: SEM images of raw biochar (RB) and iron-modified BC (FMBC).

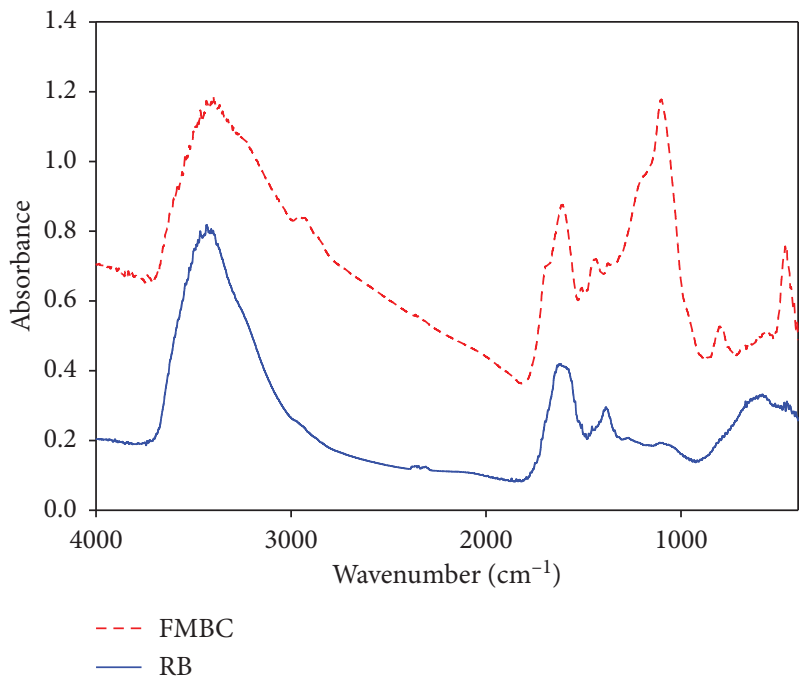

FIgURE 2: FTIR spectra of RB and FMBC.

3.3. Effect of Initial Concentration. Figure 6 shows the effect of initial concentration of $\mathrm{As}(\mathrm{V})$ ion solution for removal at a $\mathrm{pH}$ of 5.0 and a constant agitation speed of $150 \mathrm{rpm}$ for $120 \mathrm{~min}$. The amount of $\mathrm{As}(\mathrm{V})$ adsorbed increased with increasing initial concentration up to $30 \mathrm{mg} / \mathrm{l}$, indicating that $\mathrm{As}(\mathrm{V})$ removal is highly concentration dependent. At lower concentrations, the amount of ions available for adsorption by a given amount of $\mathrm{BC}$ is less than the available sites on the adsorbent. However, at higher concentrations, the number of available sites for adsorption decreases. These results indicate that the adsorption removal of the $\mathrm{As}(\mathrm{V})$ ions depends on the initial concentration. Figure 3 shows the removal efficiency of FMBC decreased from 91.5 to $63.5 \%$ when the concentration increased from 4 to $30 \mathrm{mg} / \mathrm{L}$.
3.4. Effect of Phase Reaction Time. The As(V) removal was also controlled by the reaction time. The rapid interaction of the $\mathrm{As}(\mathrm{V})$ ions to be removed by $\mathrm{BC}$ is desirable and beneficial for practical removal of arsenic anions from aqueous solutions or wastewater. Figure 7 shows the effects of reaction time for arsenic ion removal by the FMBC. For a given concentration of $\mathrm{As}(\mathrm{V})$, the amount of adsorbed $\mathrm{As}(\mathrm{V})$ ions was almost proportional to the increasing reaction time up to $45 \mathrm{~min}$. The adsorption equilibrium was obtained at a reaction time of $90 \mathrm{~min}$, with an adsorption capacity of $23.57 \mathrm{mg} / \mathrm{g}$. The adsorption rate was relatively fast at the initial adsorption stage but then slowed down gradually after more sites were occupied by the adsorbed $\mathrm{As}(\mathrm{V})$ ions. The slower adsorption was due to the gradual decrease in the number of available adsorption sites.

3.5. Adsorption Isotherm. The adsorption isotherm data of FMBC were fitted to the Langmuir and Freundlich isotherms were fitted to the Langmuir adsorption isotherm $\left(R^{2}=0.9955\right)$ $(p<0.01)$ than the Freundlich isotherm $\left(R^{2}=0.9360\right)(\mathrm{Ta}-$ ble 1). The results showed a monolayer $\mathrm{As}(\mathrm{V})$ adsorption onto the adsorption sites of the iron-modified biochar. The maximum adsorption capacities $\left(q_{\max }\right)$ of $\mathrm{As}(\mathrm{V})$ decreased in the order of FMBC $\left(28.49 \mathrm{mg} \cdot \mathrm{g}^{-1}\right)>\mathrm{RB}\left(10.3 \mathrm{mg} \cdot \mathrm{g}^{-1}\right)$. The controls showed that the As(V) adsorption capacity of FMBC was higher than that of RB. The adsorption capacity of FMBC may relate to the increasing number of surface functional groups of the modified material. The maximum adsorption capacity of the $\mathrm{FMBC}$ for $\mathrm{As}(\mathrm{V})$ ions, based on the Langmuir isotherm, was $28.49 \mathrm{mg} / \mathrm{g}$. Table 2 compares this study's result for the $\mathrm{As}(\mathrm{V})$ adsorption capacity of FMBC with values reported from other similar studies. The adsorption capacity of FMBC was much higher than that of other commercial material, and the FMBC can be utilized as a green adsorbent for the removal of $\operatorname{As}(\mathrm{V})$ in groundwater. 


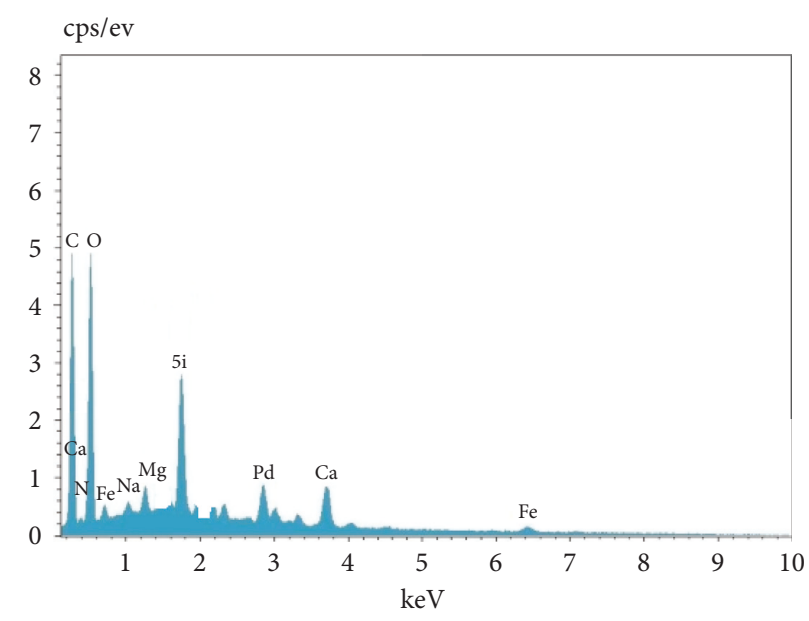

(a)

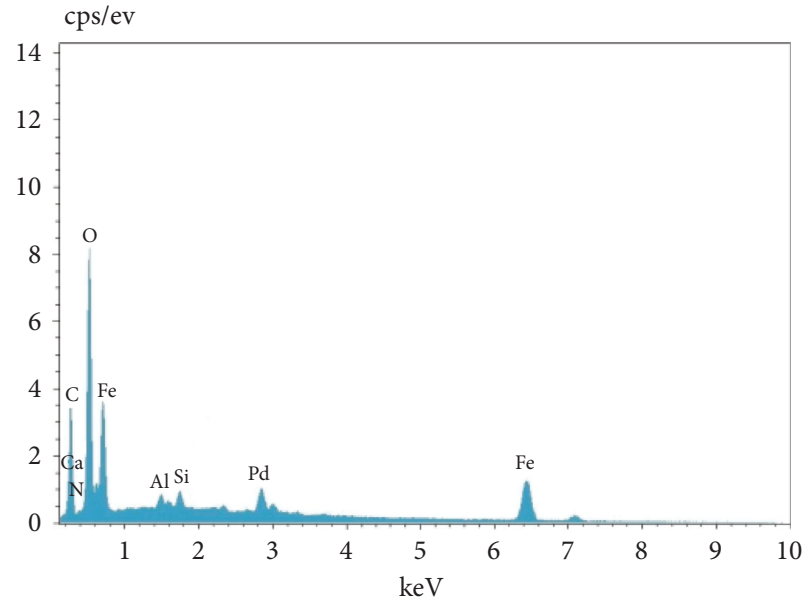

(b)

FIgURE 3: EDX spectra of RB (a) and FMBC (b).

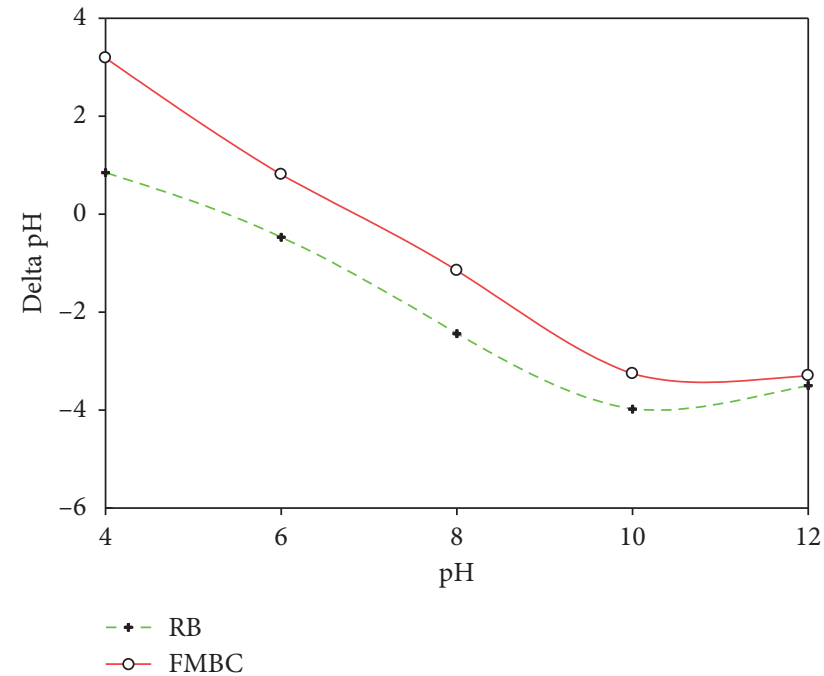

Figure 4: $\mathrm{pH}_{\mathrm{pzc}}$ of $\mathrm{RB}$ and FMBC.

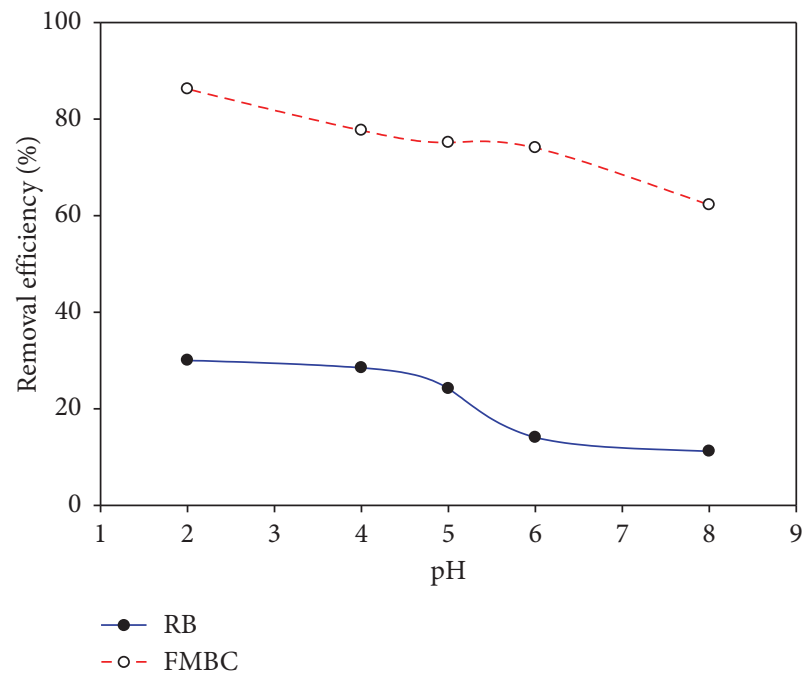

Figure 5: Effect of $\mathrm{pH}$ for the $\mathrm{As}(\mathrm{V})$ removal on $\mathrm{RB}$ and FMBC.

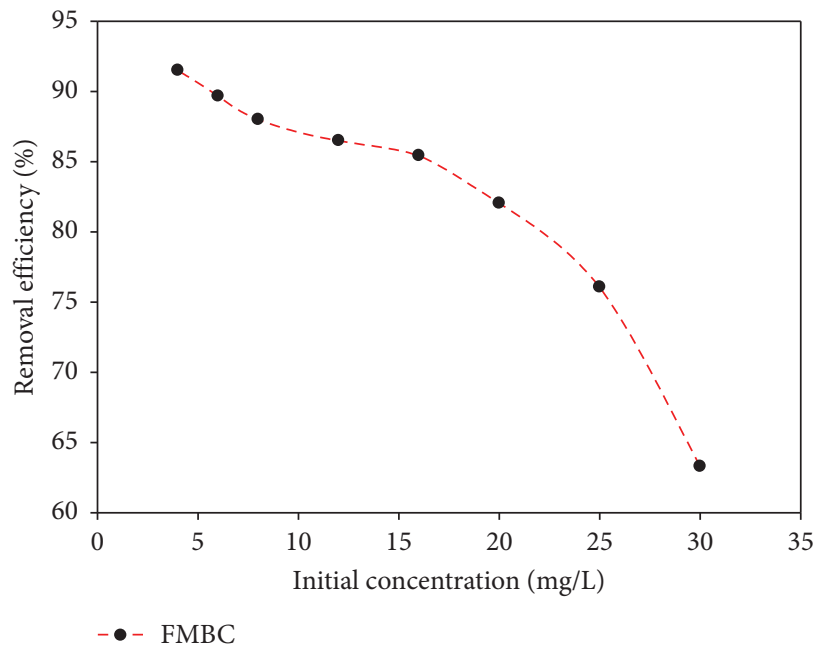

FIGURE 6: Effect of initial concentration for the As(V) removal on FMBC.

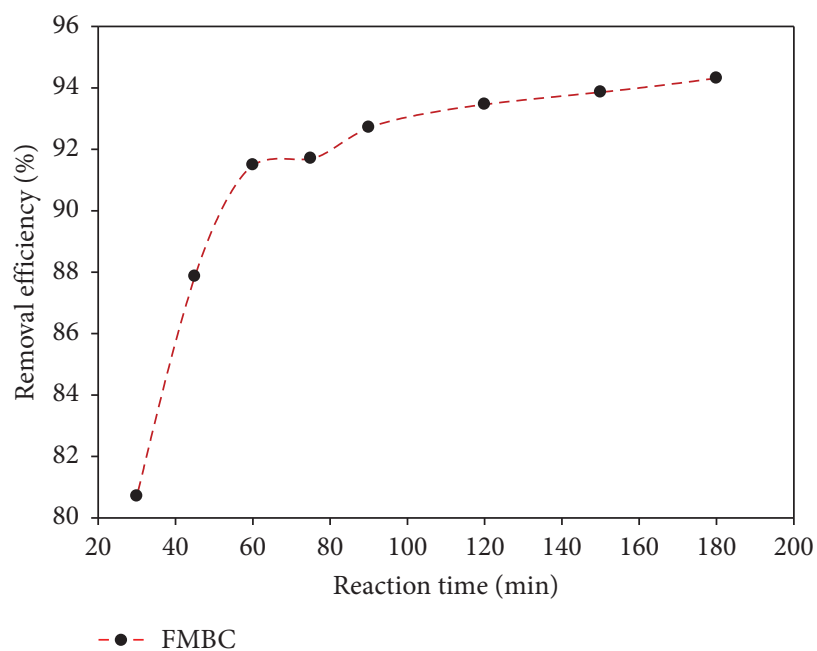

FIgURE 7: Effect of reaction time for the As(V) removal on FMBC. 
TABLE 1: Adsorption isotherm of Fe-modified BC.

\begin{tabular}{cccccr}
\hline & & \multicolumn{3}{c}{ Langmuir isotherm } & \multicolumn{2}{c}{ Freundlich isotherm } \\
& $q_{\max }(\mathrm{mg} / \mathrm{g})$ & $K_{\mathrm{L}}$ & $R^{2}$ & $\ln K_{\mathrm{F}}$ & $1 / n$ \\
\hline Fe1-BC & 28.49 & 0.563 & 0.9955 & 2.2118 & 0.5128 \\
\hline
\end{tabular}

TABle 2: Adsorption comparison with other studies.

\begin{tabular}{lcr}
\hline Material & Adsorption capacity $(\mathrm{mg} / \mathrm{g})$ & Reference \\
\hline $\mathrm{TiO}_{2}-\mathrm{CNTs}$ & 1.8 & {$[26]$} \\
Biochar & 7.21 & {$[27]$} \\
Supported nanoscale zero-valent iron on activated & 12.0 & {$[28]$} \\
carbon & 16.56 & {$[29]$} \\
Ascorbic acid-coated $\mathrm{Fe}_{3} \mathrm{O}_{4}$ nanoparticles & 25 & [30] \\
Activated carbon & 28.49 & This study \\
FMBC & 34.46 & {$[30]$} \\
Activated carbon $\mathrm{Al}_{2} \mathrm{O}_{3} / \mathrm{Fe}(\mathrm{OH})_{3}$ & 36.63 & {$[31]$} \\
\hline
\end{tabular}

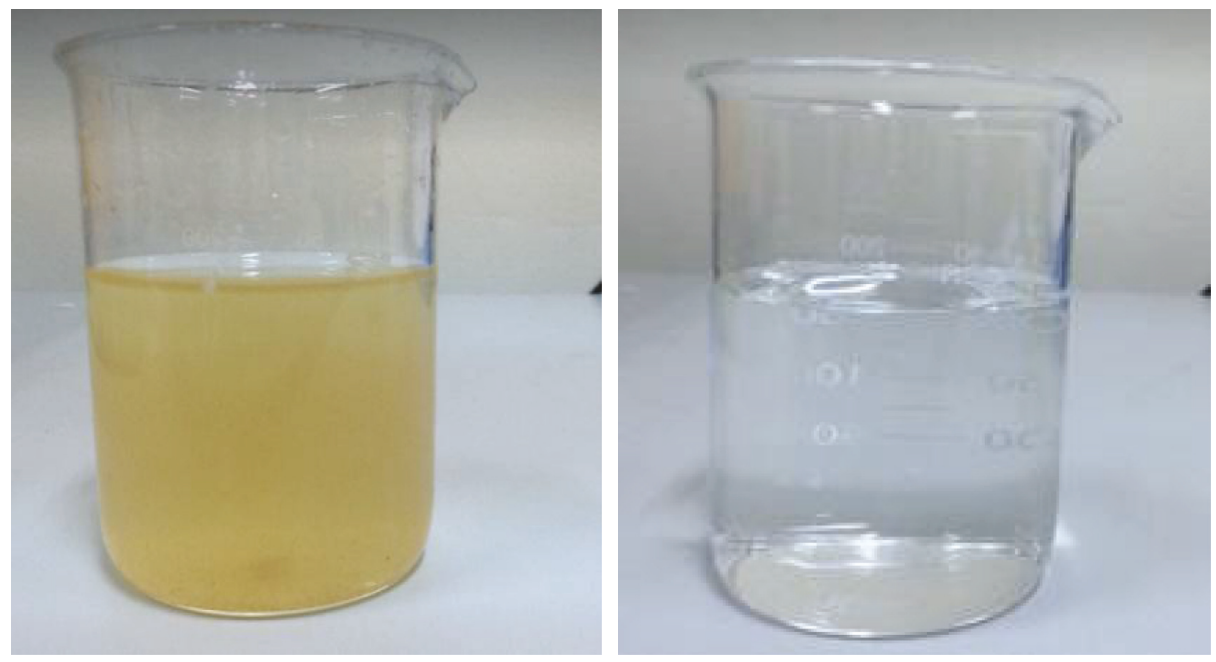

Figure 8: Groundwater sample before and after treatment.

The FMBC was applied for the removal of As $(\mathrm{V})$ in the groundwater sample which had the concentration of As(V) $91 \mu \mathrm{g} / \mathrm{L}$. Figure 8 shows the groundwater sample before and after treatment. The testing experiments showed that $1 \mathrm{~kg}$ of the Fe-modified BC can treat 278 and $141 \mathrm{~m}^{3}$ of contaminated groundwater to clean water of $50 \mu \mathrm{g} / \mathrm{L}$ and $10 \mu \mathrm{g} / \mathrm{L}$ $\mathrm{As}(\mathrm{V})$ based on the regulation of Vietnam for water supply and drinking water, respectively.

3.6. Adsorption Kinetics. Pseudo-first- and pseudo-secondorder models were utilized to determine the kinetics of $\mathrm{As}(\mathrm{V})$ removal. The kinetic model of FMBC for As(V) in the aqueous solutions is shown in Table 3. The adsorption experimental data were best described by the pseudo-secondorder kinetics that was proved by the obtained values of correlation coefficient $\left(R^{2}=0.988\right)$ to describe the adsorption behavior of $\mathrm{As}(\mathrm{V})$ onto the modified BC. The experimentally obtained adsorption capacity $\left(q_{\mathrm{e}(\exp )}\right)$ values were close to the calculated data from the pseudo-second-order model, which also showed good evidence to support the pseudo-second-order model and chemisorption [32]. For the pseudo-first-order kinetic model, the calculated adsorption capacity $\left(q_{\mathrm{e}(\mathrm{cal})}\right)$ was much lower than the experimental value $\left(q_{\mathrm{e}(\exp )}\right)$ and the determination coefficient $\left(R^{2}\right)$ was low $\left(R^{2}=0.844\right)$.

Figure 9 presents the intraparticle diffusion model for sorption by the FMBC. The adsorption processes of As(V) are related by two steps-the first step depicting macropore diffusion and the second micropore diffusion [33]. In the first stage, the sharper portion may be considered as an external surface adsorption or faster adsorption stage. The second phase describes the gradual adsorption stage, where intraparticle diffusion is rate-controlled. These results of $\mathrm{As}(\mathrm{V})$ adsorption showed only the pore diffusion adsorption. The rate of uptake might be limited by the size of the adsorbate molecule, the concentration of the adsorbate and its affinity to the adsorbent, the diffusion coefficient of the adsorbate in the bulk phase, the pore-size distribution of the adsorbent, and the degree of mixing [34]. The first and second phases can be attributed to the external mass transfer and intraparticle diffusion mechanisms, respectively [35- 
TABLE 3: Kinetic adsorption models.

\begin{tabular}{lcccccc}
\hline \multirow{2}{*}{$q_{\mathrm{e}(\exp )}(\mathrm{mg} / \mathrm{g})$} & \multicolumn{3}{c}{ Pseudo-first-order model } & \multicolumn{3}{c}{ Pseudo-second-order model } \\
& $q_{\mathrm{e}(\mathrm{cal})}(\mathrm{mg} / \mathrm{g})$ & $K_{1}(\mathrm{~g} / \mathrm{mg} / \mathrm{min})$ & $R^{2}$ & $q_{\mathrm{e}(\mathrm{cal})}(\mathrm{mg} / \mathrm{g})$ & $K_{2}(\mathrm{~g} / \mathrm{mg} / \mathrm{min})$ & $R^{2}$ \\
\hline 28.49 & 3.238 & 0.0051 & 0.844 & 30.53 & 0.0892 & 0.988 \\
\hline
\end{tabular}

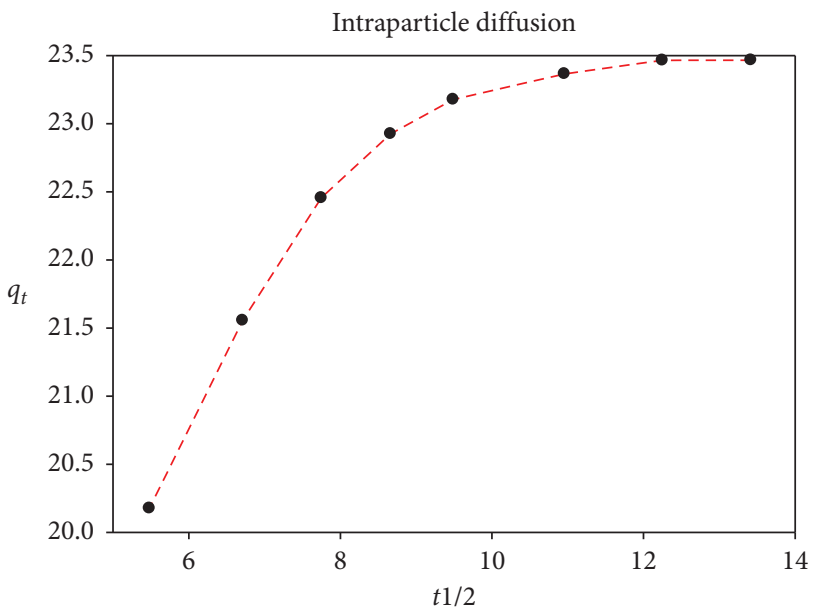

Figure 9: Intraparticle diffusion model for $\mathrm{As}(\mathrm{V})$ removal by the FMBC.

37]. Furthermore, the regression did not pass through the origin, showing that the intraparticle diffusion is not the only rate-controlling step in the sorption process. Thus, it can be inferred that external mass transfer and intraparticle diffusion occurred simultaneously during the As(V) sorption onto the Fe-modified BC.

The pseudo-second-order model and Langmuir isotherm usually assume that chemisorption of $\mathrm{As}(\mathrm{V})$ on FMBC is the rate-limiting step; it is inferred that $\mathrm{As}(\mathrm{V})$ was likely adsorbed on the surface of FMBC via chemical interaction. The proposed mechanisms of the removal of $\mathrm{As}(\mathrm{V})$ onto the FMBC through the complexation with iron are shown in the following equations:

$$
\begin{gathered}
\mathrm{FeOH}+\mathrm{H}_{3} \mathrm{AsO}_{4} \longrightarrow \mathrm{FeH}_{2} \mathrm{AsO}_{4}+\mathrm{H}_{2} \mathrm{O} \\
\mathrm{FeOH}+\mathrm{H}_{2} \mathrm{AsO}_{4}{ }^{-} \longrightarrow \mathrm{FeH}_{2} \mathrm{AsO}_{4}{ }^{-}+\mathrm{H}_{2} \mathrm{O} \\
\mathrm{FeOH}+\mathrm{HAsO}_{4}{ }^{2-} \longrightarrow \mathrm{FeAsO}_{4}{ }^{2-}+\mathrm{H}_{2} \mathrm{O}
\end{gathered}
$$

\section{Conclusion}

This study investigated the removal of $\mathrm{As}(\mathrm{V})$ from aqueous solution using iron-modified biochar (FMBC) produced from the slow pyrolysis of rice straw. The FMBC afforded maximum adsorption at a $\mathrm{pH}$ of 5.0. The adsorption data were strongly correlated with the Langmuir adsorption isotherm, indicating surface homogeneity and unilayer adsorption. The equilibrium sorption capacity of $28.49 \mathrm{mg} \cdot \mathrm{g}^{-1}$ for As(V), as determined from the Langmuir isotherm, was very high compared to that of previously reported adsorbents. The As(V) adsorption was well fitted with the pseudo-second-order kinetic model $\left(R^{2}=0.988\right)$ which showed good evidence to support the chemisorptions of As $(\mathrm{V})$ onto Fe-modified BC. The arsenic removal capacity of the FMBC is comparable to that of many commercial water treatment agents, including AC. Because the FMBC can be produced from rice straw relatively inexpensively, this simple activation method can also be applied to other thermally produced BCs to create an alternative and valueadded sorbent for arsenic removal in groundwater.

\section{Data Availability}

The data used to support the findings of this study are available from the corresponding author upon request.

\section{Conflicts of Interest}

The authors declare that they have no conflicts of interest.

\section{Acknowledgments}

This research was funded by Vietnam National University, Hanoi (VNU), under project no. QG.19.19.

\section{References}

[1] National Research Council (NRC), Arsenic in Drinking Water, The National Academies Press, Washington, DC, USA, 1999.

[2] S. Hu, J. Lu, and C. Jing, "A novel colorimetric method for field arsenic speciation analysis," Journal of Environmental Sciences, vol. 24, no. 7, pp. 1341-1346, 2012.

[3] A. Rana, N. Kumari, M. Tyagi, and S. Jagadevan, "Leaf-extract mediated zero-valent iron for oxidation of Arsenic (III): preparation, characterization and kinetics," Chemical Engineering Journal, vol. 347, pp. 91-100, 2018.

[4] J. Kim and M. M. Benjamin, "Modeling a novel ion exchange process for arsenic and nitrate removal," Water Research, vol. 38, no. 8, pp. 2053-2062, 2004.

[5] M.-C. Shih, "An overview of arsenic removal by pressuredrivenmembrane processes," Desalination, vol. 172, no. 1, pp. 85-97, 2005.

[6] S. K. Gupta and K. Y. Chen, Journal (Water Pollution Control Federation), pp. 493-506, Wiley, Hoboken, NY, USA, 1978.

[7] A. H. Sulaymon and K. W. Ahmed, "Competitive adsorption of furfural and phenolic compounds onto activated carbon in fixed bed column," Environmental Science \& Technology, vol. 42, no. 2, pp. 392-397, 2008.

[8] Y. Yao, B. Gao, H. Chen et al., "Adsorption of sulfamethoxazole on biochar and its impact on reclaimed water irrigation," Journal of Hazardous Materials, vol. 209-210, pp. 408-413, 2012.

[9] M. Inyang, B. Gao, P. Pullammanappallil, W. Ding, and A. R. Zimmerman, "Biochar from anaerobically digested sugarcane bagasse," Bioresource Technology, vol. 101, no. 22, pp. 8868-8872, 2010.

[10] C. Peiris, O. Nayanathara, C. M. Navarathna et al., "The influence of three acid modifications on the physicochemical 
characteristics of tea-waste biochar pyrolyzed at different temperatures: a comparative study," RSC Advances, vol. 9, no. 31, pp. 17612-17622, 2019.

[11] L. Lin, W. Qiu, D. Wang, Q. Huang, Z. Song, and H. W. Chau, "Arsenic removal in aqueous solution by a novel Fe-Mn modified biochar composite: characterization and mechanism," Ecotoxicology and Environmental Safety, vol. 144, pp. 514-521, 2017.

[12] Z. Qi, T. P. Joshi, R. Liu, Y. Li, H. Liu, and J. Qu, "Adsorption combined with superconducting high gradient magnetic separation technique used for removal of arsenic and antimony," Journal of Hazardous Materials, vol. 343, pp. 36-48, 2018.

[13] X. Hu, Z. Ding, A. R. Zimmerman, S. Wang, and B. Gao, "Batch and column sorption of arsenic onto iron-impregnated biochar synthesized through hydrolysis," Water Research, vol. 68, pp. 206-216, 2015.

[14] M. Zhang, B. Gao, S. Varnoosfaderani, A. Hebard, Y. Yao, and M. Inyang, "Preparation and characterization of a novel magnetic biochar for arsenic removal," Bioresource Technology, vol. 130, pp. 457-462, 2013.

[15] B. Mandal and K. T. Suzuki, "Arsenic round the world: a review," Talanta, vol. 58, no. 1, pp. 201-235, 2002.

[16] J. Gimenez, M. Martinez, J. Depablo, M. Rovira, and L. Duro, "Arsenic sorption onto natural hematite, magnetite, and goethite," Journal of Hazardous Materials, vol. 141, no. 3, pp. 575-580, 2007.

[17] K. Ramirez-Muñiz, F. Jia, and S. Song, "Adsorption of As(V) in aqueous solutions on porous hematite prepared by thermal modification of a siderite-goethite concentrate," Environmental Chemistry, vol. 9, no. 6, pp. 512-520, 2012.

[18] A. G. Karunanayake, N. Bombuwala Dewage, O. A. Todd et al., "Salicylic acid and 4-nitroaniline removal from water using magnetic Biochar: an environmental and analytical experiment for the undergraduate laboratory," Journal of Chemical Education, vol. 93, no. 11, pp. 1935-1938, 2016.

[19] M. V. Lopez-Ramon, F. Stoeckli, C. Moreno-Castilla, and F. Carrasco-Marin, "On the characterization of acidic and basic surface sites on carbons by various techniques," Carbon, vol. 37, no. 8, pp. 1215-1221, 1999.

[20] S. Wang, B. Gao, Y. Li, A. E. Creamer, and F. He, "Adsorptive removal of arsenate from aqueous solutions by biochar supported zero-valent iron nanocomposite: batch and continuous flow tests," Journal of Hazardous Materials, vol. 322, pp. 172-181, 2017.

[21] S. Deng and Y.-P. Ting, "Characterization of PEI-modified biomass and biosorption of $\mathrm{Cu}(\mathrm{II}), \mathrm{Pb}(\mathrm{II})$ and $\mathrm{Ni}(\mathrm{II})$," Water Research, vol. 39, no. 10, pp. 2167-2177, 2005.

[22] F. Fu and Q. Wang, "Removal of heavy metal ions from wastewaters: a review," Journal of Environmental Management, vol. 92, no. 3, pp. 407-418, 2011.

[23] A. Mukherjee, A. R. Zimmerman, and W. Harris, "Surface chemistry variations among a series of laboratory-produced biochars," Geoderma, vol. 163, no. 3-4, pp. 247-255, 2011.

[24] M. J. Baniamerian, S. E. Moradi, A. Noori, and H. Salahi, "The effect of surface modification on heavy metal ion removal from water by carbon nanoporous adsorbent," Applied Surface Science, vol. 256, no. 5, pp. 1347-1354, 2009.

[25] K. Henke, Arsenic in Natural Environments, John Wiley \& Sons, Hoboken, NJ, USA, 2009.

[26] H. Liu, K. Zuo, and C. D. Vecitis, "Titanium dioxide-coated carbon nanotube network filter for rapid and effective arsenic sorption," Environmental Science \& Technology, vol. 48, no. 23, pp. 13871-13879, 2014.
[27] N. K. Niazi, I. Bibi, M. Shahid et al., "Arsenic removal by perilla leaf biochar in aqueous solutions and groundwater: an integrated spectroscopic and microscopic examination," Environmental Pollution, vol. 232, pp. 31-41, 2018.

[28] H. Zhu, Y. Jia, X. Wu, and H. Wang, "Removal of arsenic from water by supported nano zero-valent iron on activated carbon," Journal of Hazardous Materials, vol. 172, no. 2-3, pp. 1591-1596, 2009.

[29] L. Feng, M. Cao, X. Ma, Y. Zhu, and C. Hu, "Superparamagnetic high-surface-area $\mathrm{Fe} 3 \mathrm{O} 4$ nanoparticles as adsorbents for arsenic removal," Journal of Hazardous Materials, vol. 217-218, pp. 439-446, 2012.

[30] X. Guo and F. Chen, "Removal of arsenic by bead cellulose loaded with iron oxyhydroxide from groundwater," Environmental Science \& Technology, vol. 39, no. 17, pp. 68086818, 2005.

[31] J. Hlavay and K. Polyák, "Determination of surface properties of iron hydroxide-coated alumina adsorbent prepared for removal of arsenic from drinking water," Journal of Colloid and Interface Science, vol. 284, no. 1, pp. 71-77, 2005.

[32] M.-F. Li, Y.-G. Liu, G.-M. Zeng, N. Liu, and S.-B. Liu, "Graphene and graphene-based nanocomposites used for antibiotics removal in water treatment: a review," Chemosphere, vol. 226, pp. 360-380, 2019.

[33] S. J. Allen, G. Mckay, and K. Y. H. Khader, "Intraparticle diffusion of a basic dye during adsorption onto sphagnum peat," Environmental Pollution, vol. 56, no. 1, pp. 39-50, 1989.

[34] P. Antonio, K. Iha, and M. E. V. Suárez-Iha, "Kinetic modeling of adsorption of di-2-pyridylketone salicyloylhydrazone on silica gel," Journal of Colloid and Interface Science, vol. 307, no. 1, pp. 24-28, 2007.

[35] G. L. Dotto and L. A. A. Pinto, "Analysis of mass transfer kinetics in the biosorption of synthetic dyes onto Spirulina platensis nanoparticles," Biochemical Engineering Journal, vol. 68, pp. 85-90, 2012.

[36] G. L. Dotto, M. L. G. Vieira, V. M. Esquerdo, and L. A. A. Pinto, "Equilibrium and thermodynamics of azo dyes biosorption onto Spirulina platensis," Brazilian Journal of Chemical Engineering, vol. 30, no. 1, pp. 13-21, 2013.

[37] N. F. Cardoso, E. C. Lima, B. Royer et al., "Comparison of Spirulina platensis microalgae and commercial activated carbon as adsorbents for the removal of Reactive Red 120 dye from aqueous effluents," Journal of Hazardous Materials, vol. 241-242, pp. 146-153, 2012. 

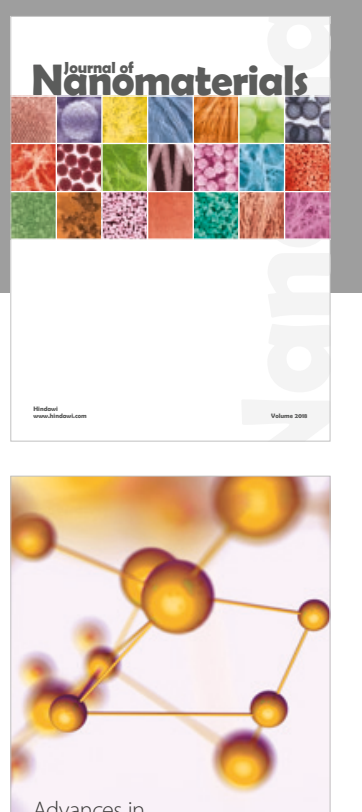

Physical Chemistry
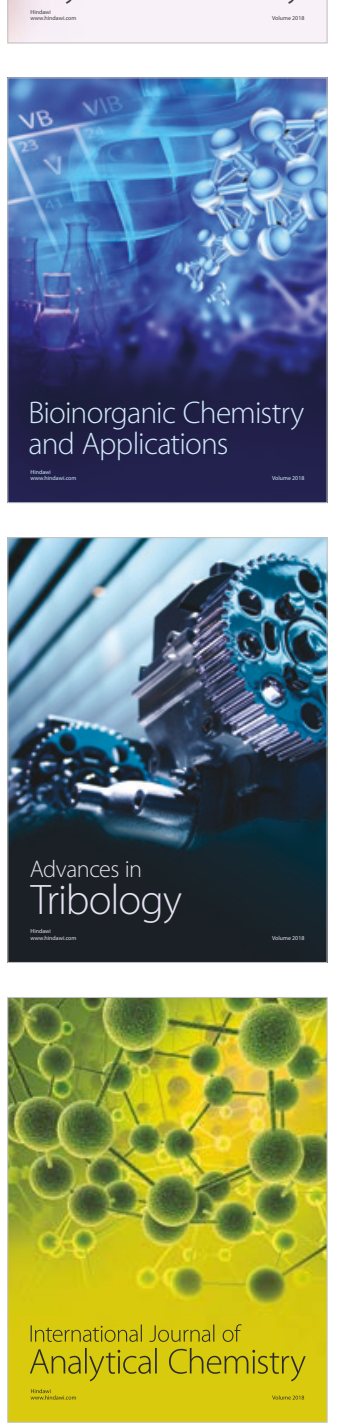

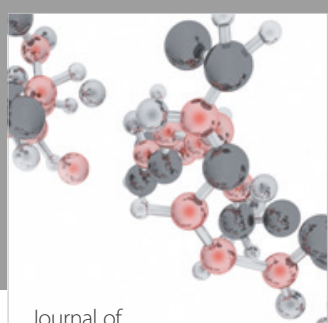

Analytical Methods

in Chemistry

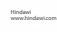

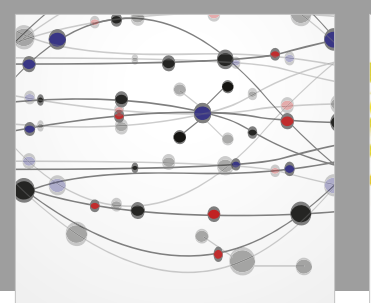

The Scientific World Journal

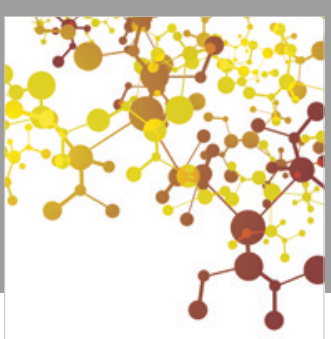

Journal of

Applied Chemistry
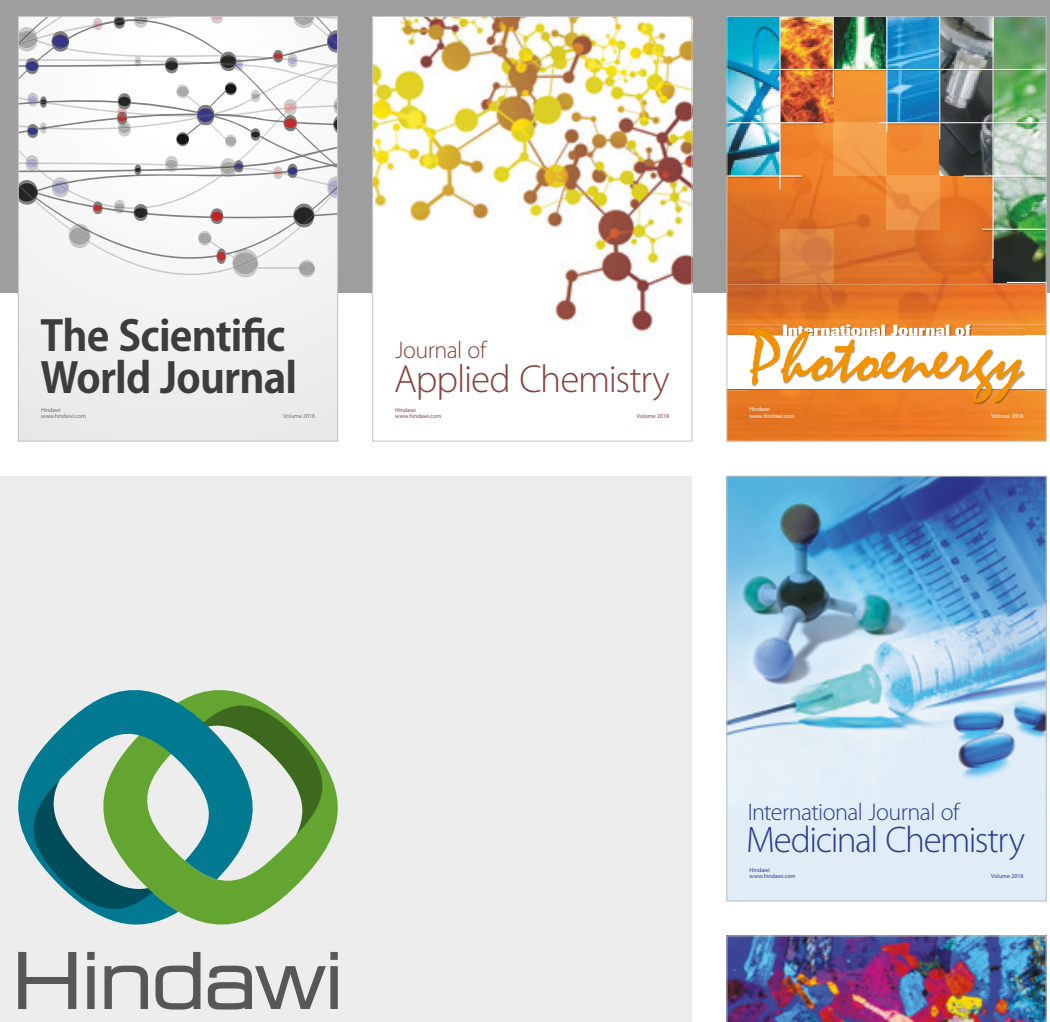

Submit your manuscripts at

www.hindawi.com
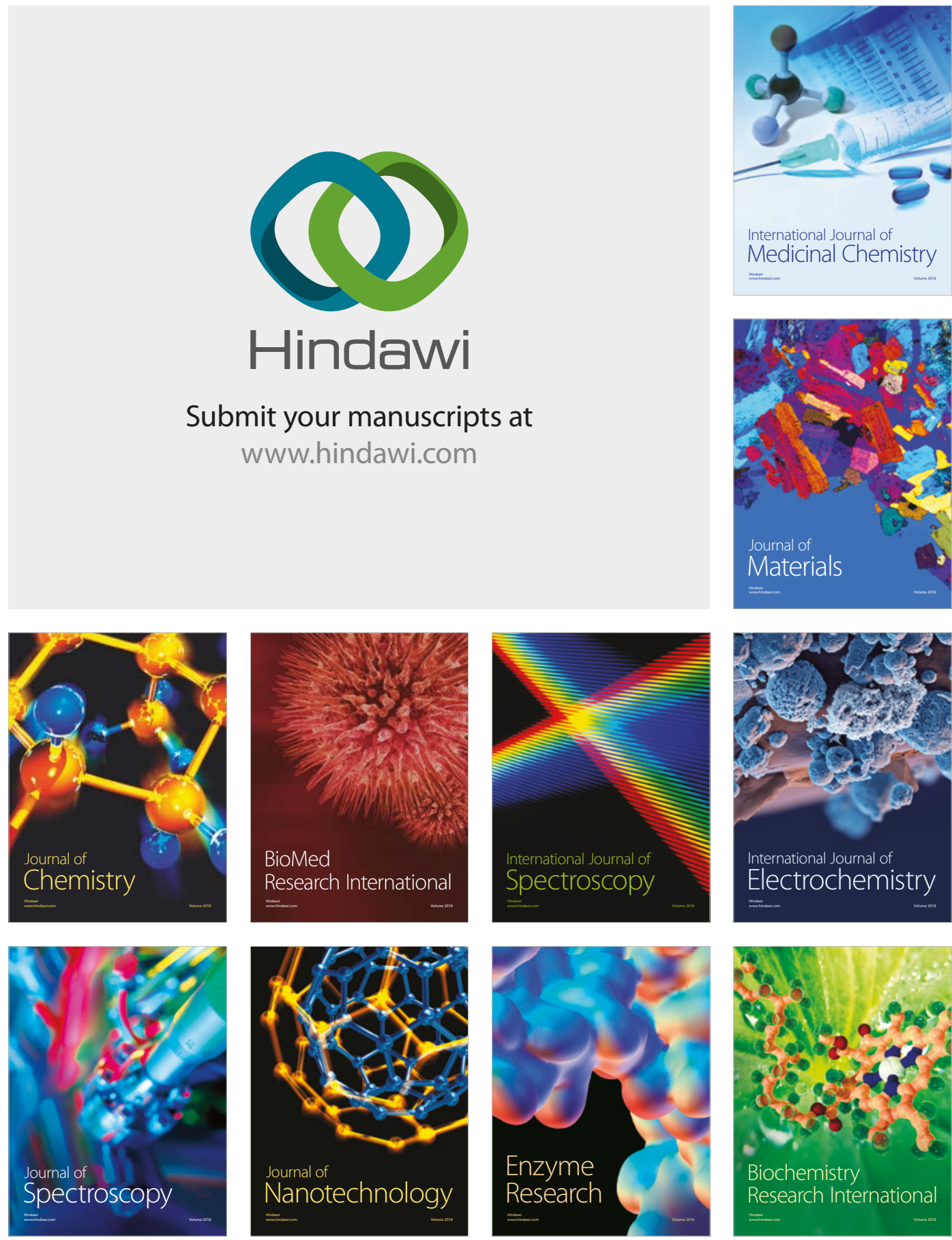
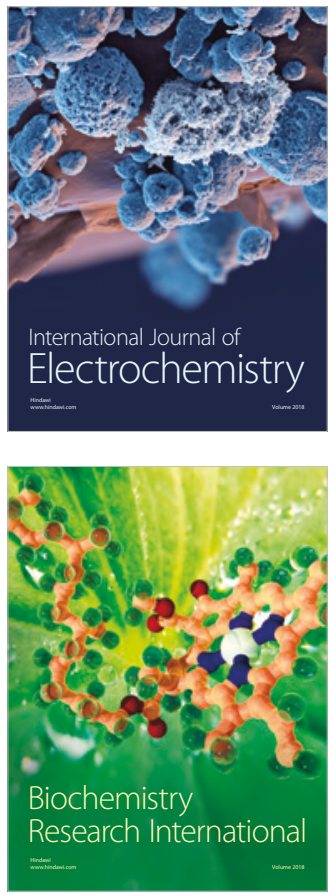